\title{
Paris is real
}

\section{Gabriela Carneiro Reis}

Doutoranda no Programa de Pós-Graduação em Geografia da Universidade Federal de

$$
\begin{gathered}
\text { Minas Gerais - UFMG } \\
\text { gabireis@live.com }
\end{gathered}
$$

Resumo: o presente trabalho tem como objetivo analisar o papel da moda nas comunidades LGBTQ+. Para atender a este objetivo, como fonte de informação, o documentário Paris is Burning foi analisado. Percebe-se o papel da moda na identidade de gênero no contexto dessas comunidades, bem como as desigualdades sociais presentes nestes territórios. É sobre estes aspectos que este trabalho se debruça.

Palavras-chave: Gênero, Geografia, moda, LGBTQ+, documentário.

Abstract: This paper aims to analyze the role of fashion in LGBTQ + communities. To do such analyze, as a source of information Paris is Burning, a documentary, has been analyzed. We can see the role of fashion in gender identity in the context, as well as the social inequalities present in these territories. It is about these aspects this work has been done.

Key words: Gender, Geography, fashion, LGBTQ +, documentary.

\section{Introdução}

Em tempos atuais é possível observar cada vez mais a abordagem de temas referentes ao gênero e sexualidade, seja nas redes sociais, nos veículos de comunicação como rádio, TV (aberta e fechada), revistas, em plataformas de entretenimento online como Netflix e Youtube, sites, dentre outros. Independentemente do meio e da forma de comunicação, o feminismo e as diversas orientações sexuais e identidades de gênero (LGBTQ+) têm se tornado pauta de inúmeros debates ao redor do mundo. Há quem procure discutir e refletir proporcionando informações esclarecedoras sobre estes assuntos e agir/atuar de forma mais inclusiva e democrática. Por outro lado, há uma "onda" de conservadorismo que tem crescido em vários países, inclusive no Brasil após a eleição do presidente Jair Bolsonaro. Uma demonstração é a ocupação do cargo de Ministra da Mulher, da Família e dos Direitos Humanos por Damares Alves, a qual causou polêmica afirmando que os meninos devem usar a cor azul e as meninas, a rosa ${ }^{1}$, além de declarar veementemente sua opinião contra a legalização do aborto no país. Apoiadores desta "onda" desqualificam e censuram debates importantes que envolvem

\footnotetext{
${ }^{1}$ Informações extraídas de reportagem do jornal El País, disponível em: https://brasil.elpais.com/brasil/2019/01/04/estilo/1546614596_209570.html
} 
estas pautas, almejando, inclusive, a manutenção dos padrões heterormativos hegemônicos.

Tendo como ponto de partida as inúmeras formas de expressão, o corpo pode ser interpretado como elemento central dessas expressões no mundo, nos espaços e na configuração de territórios. No contexto de Belo Horizonte, foi realizado neste ano (2019) o primeiro Festival Drag de Rua - Eleganza ${ }^{2}$. O festival ocupou um bar da região leste da cidade com a arte drag através de shows, desfiles e duelos A indústria da moda também está atenta às manifestações sociais enquanto clamor por mais igualdade e combate aos diferentes preconceitos (racismo, homofobia, gordofobia, etc.). Um exemplo foi a semana de moda de São Paulo, a São Paulo Fashion Week - SPFW, em que os desfiles de moda privilegiaram o discurso de inclusão na passarela e contrataram modelos negros e modelos "fora" do então padrão vigente: corpos magros e altos. Algumas das marcas que desfilaram apostaram em roupas sem gênero, por exemplo ${ }^{3}$, e outras incluíram Sam Porto, o primeiro modelo homem trans a desfilar na $\mathrm{SPFW}^{4}$.

Diante deste cenário, este artigo tem como objetivo analisar o papel da moda nas comunidades LGBTQ+ enquanto forma de manifestação das identidades, dos corpos, nos territórios. Para a realização desta análise foram utilizadas as informações do documentário Paris is Burning, lançado em 1990. Filmado no bairro Harlem, em Nova York, Estados Unidos, Paris is Burning retrata a realidade das comunidades LGBTQ+e a ralação com os bailes (Ball), onde ocorrem concursos e premiações para as diversas categorias temáticas criadas para competição. Nessas categorias, as roupas e as performances possuem papéis decisivos para garantirem os prêmios daqueles que desfilam e competem nestes bailes.

A escolha deste documentário se deve pela atualidade das questões abordadas e, também, pela importância da moda como instrumento para a construção de uma imagem e identidade específica. No decorrer do longa, percebem-se referências a questões relacionadas ao gênero, à sexualidade, aos preconceitos, à exclusão e às desigualdades sociais. Tais fatos são relatados através das falas dos entrevistados e também são analisadas neste artigo.

\footnotetext{
${ }^{2}$ Informações extraídas de reportagem do site BHAZ. Disponível em: https://bhaz.com.br/2019/09/18/bhfestival-drag-de-rua-de-gracal.

${ }^{3}$ Informações extraídas de reportagem do site Fashion Foward - FFW. Disponível em: https://ffw.uol.com.br/noticias/moda/edicao-historica-do-spfw-traz-irreversivel-quebra-de-padroesdentro-e-fora-das-passarelas/

${ }^{4}$ Informações extraídas de reportagem do site Fashion Foward - FFW. Disponível em: https://ffw.uol.com.br/noticias/moda/conheca-sam-porto-o-primeiro-homem-trans-a-desfilar-no-spfw/.
} 
Ainda que o documentário tenha sido rodado no contexto da década de 1980 e em Nova York, o mesmo possui relevância para esta análise, devido ao papel fascinante que a vestimenta possui e para o entendimento das questões relacionadas às diferentes sexualidades e identidades de gênero. Após quase 30 anos do lançamento, Paris is

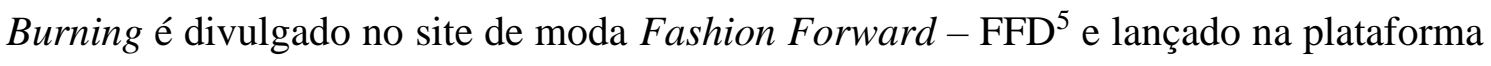
de entretenimento Netflix, através da qual a presente autora teve contato com o documentário em questão.

Para a construção deste artigo, primeiramente, abordou-se sobre a trajetória da questão do gênero na Geografia. Para tanto, publicações que datam da década de 1990 foram consideradas. Algumas referências trazem consigo informações sobre o gênero feminino, especificamente. Tais contribuições foram relevantes na medida em que abordam temas referentes ao trabalho, trabalho doméstico, capitalismo, machismos e formas de violência contra a mulher. Ainda que muitos dos textos citados façam referências diretas ao gênero feminino, entende-se que a extensão desta violência e dos preconceitos à comunidade LGBTQ+ tenha relação com as formas de dominação sobre a mulher e, portanto, sobre as diferentes formas de apropriação do feminino, seja em corpos do sexo masculino ou do sexo feminino. Por isso, considerou-se importante apresentar aspectos dessa trajetória neste trabalho. Percebe-se, dessa forma, que a violência de gênero tem origem na dominação e no mito de superioridade dos homens sobre as mulheres. Assim, aqueles que fogem aos preceitos heteronormativos são excluídos, e/ou marginalizados e/ou violentados de diferentes formas.

Em seguida, buscou-se por referências sobre o tema moda com a finalidade de verificar como as vestimentas podem servir como forma de expressão das diferentes identidades e representação nos territórios. Procurou-se verificar como a moda pode conferir um poder de diferenciação perante o outro através da imagem e identidade que se deseja transmitir. A moda é considerada neste trabalho como expressão individual, coletiva, social, econômica e cultural. Entende-se, dessa forma, que a indumentária pode conferir aos indivíduos um poder de representação incidente e atuante no(s) território(s).

Para a análise do documentário, recorreu-se às falas dos entrevistados, bem como às cenas que registram alguns dos trajes exibidos no contexto dos bailes. Como forma de complementação das informações expostas, foram coletados dados disponíveis

\footnotetext{
${ }^{5}$ Informações extraídas da reportagem do site Fashion Foward - FFW. Disponível em: https://ffw.uol.com.br/noticias/cultura-pop/paris-is-burning-assista-ao-doc-que-ainda-e-necessario-einspirador-quase-30-anos-mais-tarde/.
} 
em sites que pudessem acrescentar e esclarecer ainda mais as informações transmitidas pelas falas e cenas do longa. Para a proposta do presente artigo, foram escolhidas algumas das categorias disputadas nos bailes, nas quais é possível perceber a relação direta com a moda. Todavia, cabe destacar que ao longo de todo o documentário é possível perceber o papel das roupas naqueles contextos, seja através das falas, ou nos bailes, pela ideia de status e diferenciação perante o outro e/ou pelo desejo de consumir roupas de grifes.

Paris is Burning expõe elementos de desigualdade social em que vivem estas comunidades. $\mathrm{O}$ (não) poder de consumo de roupas, por exemplo, é um destes elementos relatado pelos entrevistados. Porém, temas como racismo e homofobia estão presentes durante todo o longa e também foram considerados nesta análise. Não se pode negar a riqueza das questões abordadas pelo documentário, as quais proporcionariam inúmeras análises. Este trabalho, no entanto, pelo viés da moda, abre caminhos para futuros questionamentos e reflexões de uma realidade documentada como vídeo, mas ainda presente nos dias de hoje.

\section{Geografia e gênero}

A discussão sobre gênero na Geografia teve início em um contexto relativamente recente. Isabel André (1990), ao traçar brevemente a evolução da Geografia Humana, informa que a partir dos anos 50, no cenário pós-guerra, a Nova Geografia trouxe novas referências para aquele contexto (ANDRÉ, 1990, p. 332). A partir dos anos 60, questões de ordem social entram em cena e o marxismo possibilita novas leituras das sociedades, diante da seguinte conjuntura mundial: "Os processos de descolonização, o subdesenvolvimento, as relações entre as superpotências, os desequilíbrios regionais, os conflitos sociais urbanos eram facilmente interpretados à luz da luta de classes ou das condições necessárias à acumulação do capital” (ANDRÉ, 1990, pgs. 332 e 333). Entretanto, a autora faz uma ressalva informando que as questões sociais não poderiam se restringir às questões de classe ou às “estratégias do capital” (ANDRÉ, 1990, p. 333).

A partir da década de 80, o gênero passou a ser considerado na Geografia Humana. André (1990, p. 335), contudo, procura delinear como este novo tema pode ser investigado na Geografia, destacando a relevância do território:

O território, como ponto de partida para o estudo dos fenômenos sociais, pode ser, em muitas situações, a melhor via para um conhecimento descompartimentado. Condições de vária ordem, cujo estudo compete a diversos domínios científicos, conjugam-se de 
múltiplas formas na definição das manifestações sociais e essa articulação concretiza-se no território (ANDRE, 1990, 335).

No final dos anos 80, estudos sobre o gênero começaram a surgir com mais frequência na Geografia, sobretudo no Reino Unido. Isto ocorreu pelo fato de haver uma baixa representatividade das mulheres em instituições internacionais, bem como pelo surgimento de debates envolvendo questões como aborto, contracepção e divórcio (ANDRÉ, 1990, pgs. 335 e 336). Todavia, apesar do desenvolvimento econômico ocorrido nas últimas décadas, a autora ressalta que não houve de fato uma igualdade entre os gêneros, apesar da entrada da mulher no mercado de trabalho. Isto se deve também pelo fato de que o "fica aparente" é o lado visível, o que é observado no domínio público e não na esfera privada. O trabalho doméstico, da esfera privada, continua a ser assegurado pela mulher. Assim, André (1990, p. 337) considera que dicotomias como público e privado, trabalho e lazer, formal e informal, por exemplo, são conceitos indissociáveis quando a questão de gênero está em análise na Geografia. A autora ainda complementa informando que a estrutura urbana é onde se registra o lugar da segregação espacial entre trabalho remunerado e trabalho doméstico.

O desenvolvimento capitalista, então, promove autonomização da produção em relação à reprodução social, segregando estes dois processos e influenciando a dinâmica familiar. O que não mudou, entretanto, foi o trabalho doméstico que continuou a existir, apresentando temporalidade própria, distinta daquela do trabalho remunerado. O tempo dedicado ao trabalho doméstico não diminuiu e nem as tarefas foram divididas entre homens e mulheres (ANDRÉ, 1990, pgs. 339 a 340). Para a autora: “A desigualdade social entre homens e mulheres e as relações que se estabelecem entre ambos têm amplitudes e formas diferenciadas nos vários grupos sociais e são condicionadas pelo tipo de desenvolvimento social e econômico que marca os diferentes territórios" (ANDRÉ, 1990, pg. 344).

Silva et al (2017) buscam evidenciar a produção acadêmica envolvendo temas como a Geografia feminista e queer. Para os autores, a maneira como a historiografia da Geografia brasileira se faz, tanto no processo de produção como de circulação, tem omitido a discussão de algumas importantes vertentes do pensamento geográfico como as Geografias feministas e queer. Diante desta análise, os autores informam que isto se deve ao desprezo que estas formas de imaginação geográfica provocam no meio acadêmico brasileiro (SILVA et al, 2013, p. 85). Escancaram o fato de que estes temas 
não fazem parte dos principais temas abordados na produção acadêmica brasileira e denunciam certa hierarquia locacional referente às universidades mais tradicionais do país. Ao traçarem esta análise, contam a trajetória em torno da discussão sobre o corpo como elemento das Geografias feministas e queer. Dessa forma, trazem considerações importantes sobre como o corpo deixou de ser concebido como elemento estático, fixo. As informações presentes neste estudo contribuem para a concepção de corpo como não linear e, portanto, contribui para as diferentes formas de expressão da sexualidade.

A fim de evidenciar algumas descontinuidades, os autores primeiramente, analisam as produções na Geografia anglo-saxã a partir da análise da relação entre corpo e espaço. No que se refere à essa trajetória, segundo os autores (2013, p. 87), durante várias décadas não houve uma vinculação do enfoque feminista na Geografia com o corpo. Apenas no final do século XX e início do XXI que o corpo passou a ser alvo minucioso no campo da Geografia e também das ciências sociais. Assim, fazem a seguinte consideração sobre os corpos no espaço:

Os corpos são materiais, possuem forma e tamanho e, inegavelmente, "ocupam" um espaço físico. Por meio de ações, os corpos produzem mercadorias. Sendo assim, estados corpóreos, como saúde, doença, força física, capacidade reprodutiva e habilidades manuais, são elementos de intensa associação entre o corpo e a sociedade e, portanto, o espaço (SILVA et al, 2013, p. 87).

A revolução industrial provocou uma série de transformações sociais e no trabalho. O ócio fez com que novas atenções fossem voltadas aos corpos, o qual se torna um corpo desejante que irá satisfazer suas necessidades através do consumo. Tem-se agora corpos saudáveis e esbeltos e vários recursos foram criados para a manutenção desses corpos, dos padrões vigentes, como academias, clínicas, etc. (SILVA et al, 2013, p. 88).

Ocorre uma superação da oposição entre corpo e mente. A vertente feminista volta sua atenção superando o não reconhecimento do corpo ao se pensar o ser humano: “A tradição de negar o corpo das análises de geógrafas feministas esteve fundamentada na ideia da supremacia da cultura na construção dos papéis de gênero, e o corpo era entendido até então como algo estático, biológico e essencializado" (SILVA et al, 2013, p. 89).

As reflexões, que possibilitaram o desmanche da dicotomia corpo e mente, permitiram a emergência das ideias de instabilidade e fluidez das identidades corporais. O corpo deixa de ser algo fixo, há a ideia de corporeidade, associada à mutabilidade e ao 
movimento. Segundo os autores (2013, p. 92), algumas obras puderam evidenciar que a Geografia percorreu algum caminho estudando a relação corpo e espaço. Porém, foi a contribuição dos estudos das sexualidades que aprofundou as análises que envolvem o corpo. Passou-se a se questionar a concepção do corpo como elemento dado e fixo, definido pela genitália, o que, por sua vez, definiria e reproduziria essas características de dualidade dos corpos. Dessa forma:

Para derrubar as hierarquias modernas produzidas pela razão, era necessário 'desnaturalizar' a organização binária dos sexos e dos desejos atrelada às formas corporais. Afinal, foi a pretensa naturalidade identificada nas características materiais dos corpos que constituiu as justificativas para a manutenção dos privilégios de alguns, com a marginalização e subordinação de outros (SILVA et al, 2013, p. 92).

Assim, a sexualidade estaria ligada à cultura, segundo as concepções de Foucault (1988), citado pelos autores:

As ideias de Foucault permitiram a concepção do corpo como algo que não é fixo e nem mesmo passivamente submetido ao poder. $\mathrm{O}$ corpo, que é alvo do poder, pode ser também o lugar de subversão de toda a disciplina que o impõe. As marcas físicas, como a anatomia sexual, a cor da pele e outras só podem ser compreendidas por meio do jogo de forças que constitui o saber/poder sobre elas, suas significações e sentidos (SILVA et al, 2013, p. 94).

Para os autores, a construção do sexo não deve ser pensada como algo natural e sim uma norma cultural que regula as materializações dos corpos, podendo incluir ou excluir aqueles que são considerados anormais (SILVA et al, 2013, p. 97). Ao citarem a contribuição de um estudo de duas geógrafas, Lynda Johnston e Robyn Longhurt (2010) ${ }^{6}$, que também abordaram a respeito dos corpos, trazem a seguinte contribuição:

Segundo elas, a Geografia pode analisar o corpo como espaço e o corpo no espaço, argumentando que nossos corpos fazem diferença em nossas experiências de espaço e lugar. Elementos como tamanho, aparência, saúde, vestimenta, comportamento, sexualidade e práticas sexuais afetam a forma como nos apresentamos aos outros e também a forma como os outros nos representam. Assim, corpos dissonantes das representações hegemônicas de gênero e práticas sexuais foram especialmente estudados na chamada geografia queer, já que esses corpos, que não obedecem ao modelo dual da sexualidade heteronormativa, constituem vidas "fora de lugar". (SILVA et al, 2013, p. 97).

${ }^{6}$ JOHNSTON, Lynda; LONGHURST, Robyn. Space, place and sex: geographies of sexualities. Rowman \& Littlefi eld: Lanham, 2010. 
O desenvolvimento das concepções sobre o corpo na Geografia esteve vinculado ao estudo das sexualidades, principalmente para a vertente queer, pois a mesma lutava para combater a ideia de linearidade natural entre sexo, gênero e desejo (SILVA et al, 2013, p. 98).

Não se pode, contudo, abordar questões de gênero sem refletir a respeito do conceito de poder. Lan (2017) procura analisar sobre a violência de gênero e sua relação com o micromachismo e traz uma importante consideração sobre o poder: "El poder no es una categoría abstracta; el poder es algo que se ejerce, en las interaciones sociales y tiene un doble efecto: opresivo, y configurador en tanto provoca uma modificación de la realidad y redefine la existencia (espacios, subjetividades y modos de relación)" (LAN, 2017, p. 177).

Sobre os micromachismos a autora informa que esse comportamento irá se converter na base da violência de gênero: "Estos microabusos y microviolencias hacen que el varón sostenga su propia superioridad de género gestando un tejido imperceptible que envuelve a la mujer, quebrantando su autonomía personal.” (LAN, 2017, p. 184). A autora ainda destaca o respaldo social que estas práticas possuem em nossa sociedade e as caracterizam como pequenas tiranias, violências brandas e manobras cotidianas, por exemplo.

Uma observação importante da autora é que as expressões do machismo são práticas sociais que justificam e promovem atitudes discriminatórias contra o feminino, sendo a base desses comportamentos o mito da superioridade masculina. Assim, o machismo pune qualquer comportamento feminino nos homens, fato que irá sustentar as bases da homofobia (LAN, 2017, p. 183).

Através das considerações dos autores, é possível observar como a questão de gênero tem sido abordada na Geografia. Ao trazer para a discussão o corpo como elemento fluido, não linear, entende-se a diversidade das identidades de gênero. As relações de poder podem ser sustentadas através dos micromachismos e se tornam bases para a violência de gênero também sobre aqueles sujeitos cujas identidades não condizem com o sexo do corpo.

\section{Sobre moda...}

Para melhor compreensão sobre a história da moda na sociedade, segue breve contextualização. Durante a história da civilização, o vestuário sofreu inúmeras 
influências diante das diferentes transformações ocorridas até se caracterizar no que se concebe como moda na atualidade. A esse respeito, Fronçois Boucher (2010) informa que as funções do vestuário acompanharam a evolução das civilizações, as quais por sua vez determinavam a do vestuário. Tais funções surgiam em consequência dos elementos essenciais das civilizações, os quais apareciam por meio de forças de ação da vanguarda, ou, por reação a essa e, até mesmo, pela estabilidade.

Fernand Braudel (1995) afirma que a história das roupas "levanta todos os problemas, os das matérias-primas, dos processos de fabrico, dos custos de produção, da fixidez cultural, das moedas, das hierarquias sociais" (BRAUDEL, 1995, p. 281). Entre os séculos XV e XVIII, o vestuário se torna um dos principais meios de afirmação social, capaz de diferenciar aqueles que pertencem às classes sociais nobres daqueles pertencentes às classes mais pobres. O luxo e a ostentação são observados nos trajes, nos sapatos, perucas, joias, dentre outros artefatos e, como efeito, "até mesmo no mercado de uma cidade basta uma olhadela para distinguir burgueses de gente do povo" (BRAUDEL, 1995, p. 281). Por outro lado, o autor pondera que se a sociedade fosse imutável o vestuário não apresentaria transformações constantes.

Segundo Braudel (1995, p. 286), a Europa dos ricos e das modas é "tomada" por caprichos responsáveis por uma pequena parcela da sociedade. Mas a moda "não é apenas abundância, quantidade e profusão. Consiste em mudar tudo a qualquer momento, uma questão de estação, de dia e de hora" (BRAUDEL, 1995, p. 286). O "império" da moda executa sua severidade após 1700 , contexto em que seu sentido é atribuído àquilo que está na atualidade, àquilo considerado novo e atual. Em contrapartida ao glamour da moda, no entanto, “à margem, fica a imensa inércia dos pobres” (BRAUDEL, 1995, p. 288).

Boucher (2010) esclarece que o desenvolvimento do vestuário pode ser dividido em três momentos. O primeiro corresponde ao período da Antiguidade até o século XIV. Neste período os trajes não são transformados de forma frequente, não expressam caráter nacional e são iguais em todas as classes. O segundo momento compreende os anos entre os séculos XIV ao XIX, em que as roupas tornam-se ajustadas e mais curtas devido ao intenso desenvolvimento industrial. $\mathrm{O}$ vestuário adquire aspectos pessoais e nacionais, sofre constantes modificações, das quais se destaca o surgimento inédito da moda, no sentido moderno da palavra. Nesta fase, a indumentária passa a ter cada vez mais relação com o contexto, no que se refere aos aspectos políticos e comerciais, e desvincula-se de qualquer vestígio religioso. A terceira e última fase inicia- 
se em meados do século XIX até a atualidade, em que o vestuário, influenciado pelo maquinismo gerador da confecção e do expansionismo europeu, torna-se cada vez mais internacional. Surge a alta-costura e os "imperativos de uma moda cada vez mais efêmera ao privilégio de uma classe em que o senso do luxo tradicional e o poder do dinheiro dominam as diferenças sociais" (BOUCHER, 2010, p. 17).

Daniela Calanca (2008, p. 13) informa que o termo "moda", por sua vez, tem sua etimologia latina: modus (modo, maneira). Seu uso esteve relacionado a mudanças frequentes, ao aspecto mutável, que não se restringia às roupas, mas, aos modos de pensar, agir e até nas convenções sociais, sobretudo para as elites. O vestuário então se apresenta como:

um fenômeno completo porque, além de propiciar um discurso histórico, econômico, etnológico e tecnológico, também, tem valência de linguagem, na acepção de sistema de comunicação, isto é, um sistema de signos por meio do qual os seres humanos delineiam a sua posição no mundo e a sua relação com ele (CALANCA, 2008, p. 16).

A indumentária, então, torna o "corpo significante", em que o "ato de vestir transforma o corpo, e essa transformação não se refere a um único significado biológico, fisiológico, mas a múltiplos significados, que vão daquele religioso, estético, àquele psicológico" (CALANCA, 2008, p. 17).

A moda na modernidade passa a ser expressa amplamente em diferentes objetos, comportamentos e pensamentos utilizados e expostos publicamente, o que remete à ideia de afirmação de identidade, de status e de poder exercido perante o outro. As novas máquinas como cinema, rádio, fotografia e mais tarde a televisão, foram responsáveis por mudanças nas convenções que predominavam pela exaltação da expressividade e beleza do corpo a partir do século XIX (CALANCA, 2008, p.138). Já no contexto do século XX, o cinema revelou estrelas que se tornaram símbolos de sensualidade, erotismo, transgressão e fascínio, como é o caso, por exemplo, de Greta Garbo, Marlene Dietrch e Bette Davis. Nessa exaltação o vestuário foi crucial.

Tem-se, então, a partir da evolução do vestuário, aspectos da sociedade e dos modos de vida variáveis no percurso do tempo. Inicialmente, os trajes, de aspecto utilitário, passam a representar status, luxo e sexualidade, em contraste ao período de poucas distinções entre as classes. Logo, a moda passa a criar uma indústria que movimenta a economia em âmbito global, gera empregos, dita tendências. $\mathrm{O}$ vestuário, aqui, é dotado de signos e se apresenta como meio de manifestação dos indivíduos, 
através do qual informa a relação com o mundo e sua posição nele. Sob esse aspecto, a moda se torna inerente às construções e manifestações humanas que acontecem em diferentes territórios.

\section{Paris is Burning: gênero, moda e geografia}

O documentário Paris is Burning relata a comunidade LGBTQ+ do bairro Harlem em Nova York, na década de 1980. O documentário é dirigido por Jennie Livingston, cineasta conhecida pelas filmagens de storytelling e por abordar temas como raça, gênero, classe e identidade. ${ }^{7}$ Paris foi premiado no Festival de Sundance ${ }^{8}$, o qual, de acordo com informações disponíveis em site próprio, acontece anualmente no estado de Utah, nos EUA, e se tornou o principal festival de original storytellers que concede premiações a séries, curtas-metragens, documentários, dentre outros, desde 1985.

Ao longo do documentário são exibidas cenas que mostram como vivem essas pessoas e a relação que possuem com os bailes locais. Relatam também os sonhos, as dificuldades, os preconceitos, a desigualdade social, a importância dos bailes e a relação com a moda, com as roupas e com a própria condição financeira em que vivem. Isso é possível observar a partir de uma das primeiras falas de um dos entrevistados. Este, ao relatar a fala do próprio pai, diz que: "Tem três coisas contra você neste mundo. Todo negro tem duas: ser negro e homem. Já você é negro, homem e gay. Vai ser difícil para caralho neste caso. Se entrar nessa vida, terá de ser mais forte do que pensava." (PARIS IS BURNING, 1990). Nesta fala é possível perceber a questão da cor e da sexualidade, bem como das restrições que ambas condições determinam para essas pessoas em uma sociedade que promove, de inúmeras formas, os padrões heteronormativos. É sob este cenário que a maioria daqueles que aparecem no documentário vivem. Os bailes, então, surgem como espaços livres para exprimir aquilo que é reprimido no "mundo real". Este sentimento de "liberdade" pode ser percebido nas seguintes falas de dois entrevistados:

"É como atravessar o espelho na história da Alice. Você entra e acha $100 \%$ correto ser gay. O mundo não é assim. O mundo não é desse jeito, mas deveria ser."

"O baile é a coisa mais próxima da realidade que teremos de toda aquela fama, fortuna, estrelato e holofotes."

\footnotetext{
${ }^{7}$ Informações extraídas do site da própria diretora, Jennie Livingston. Disponível em: https://www.jennielivingston.com/about.

${ }^{8}$ Para mais informações ver site Sundance Institute. Disponível em: https://www.sundance.org/festivals/sundance-film-festival.
} 
"Os bailes são mais ou menos a fantasia de sermos estrelas. Como no Oscar e tal. Ou desfilar como uma modelo. Muitos dos que vêm aos bailes não têm onde cair mortos. Alguns não têm nem o que comer."

"Um baile significa ser qualquer coisa que você deseje ser."

"No baile, é possível exibir sua arrogância, sedução, beleza, sagacidade, encanto, saber. Você poder ser e fazer qualquer coisa, aqui e agora, ninguém vai questionar.” (PARIS IS BURNING, 1990).

Enquanto os entrevistados do documentário expressam seus sentimentos e sua relação com os bailes, como foi descrito nas falas acima, cenas com imagens de revistas, lojas e marcas de moda como a Chanel $^{9}$, por exemplo, são exibidas. Uma das entrevistadas, Pepper Labeija, uma das drags que mais ganhou prêmios nos bailes, declara sua admiração pelo "mundo" dos ricos e pelo poder de compra dos mesmos:

"Sempre vi como os ricos viviam, e era como levar um tabefe na cara. Eu queria ter aquilo porque nunca me senti à vontade sendo pobre. Não me sinto. Nem ser classe média combina comigo. Ao ver os ricos como as pessoas viviam em Dinastia, aquelas casas enormes. Eu pensava: 'Eles têm casas de 42 cômodos. Meu Deus, que tipo de casa é essa?' A nossa tem três. Por que podem ter isso e eu não? Me sentia de fora. Sempre me senti excluída dessas coisas" (PARIS IS BURNING, 1990).

Além da relação com os bailes, as desigualdades sociais também são expressas e fazem contraste com as imagens que são exibidas enquanto Labeija desabafa: cenas de mansões, lojas de moda, roupas de grifes, lifestyle dos ricos (como hipismo) e carros. Tal contraste declara a exclusão ao acesso a bens materiais e a certos espaços urbanos, criando assim uma ilusão de que o tipo de vida das pessoas ricas seja somente o tipo ideal.

O baile também representa um espaço para adquirir fama, principalmente, se a pessoa for premiada em alguma categoria. Determinadas falas declaram certo fascínio por essa fama e até almejam isso. A Imagem 1 - Ball é o recorte de algumas cenas dos desfiles que ocorrem nas categorias dos bailes:

\footnotetext{
${ }^{9}$ Para maiores informações, consultar site da marca, disponível em: https://www.chanel.com/pt_BR/.
} 
Imagem 1- Ball

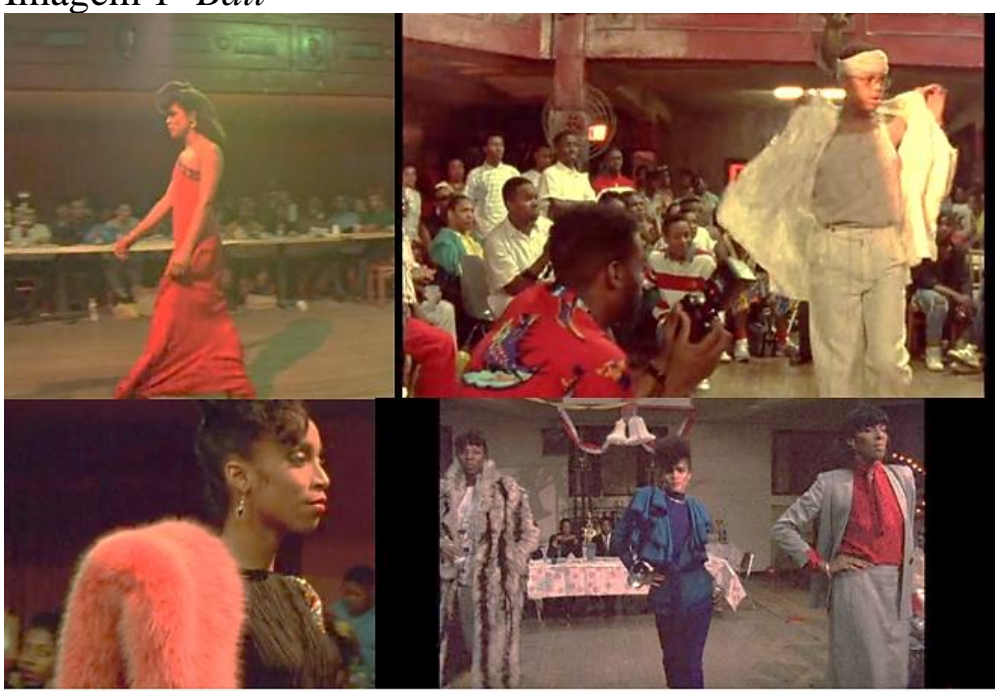

Fonte: imagem extraída do documentário Paris in Burning (1990)

Durante o baile, categorias temáticas entram em cena e são palco para as disputas entre os participantes. Como prêmio os vencedores ganham troféus. Algumas categorias são citadas e apresentadas no documentário: Alta-Costura Esportiva Inverno, Alta-costura Noite, Alta-costura Parisiense, School (escola); Urbano e Rural, Machona Montada em um Baile, Opulência, Drag Machona, dentre outras. É no desfile de cada categoria que os trajes aparecem.

Através da Imagem 1, pode-se dizer que as roupas representam a expressão da identidade e da identidade de gênero (geralmente o gênero feminino). Isto pode ser observado através das falas, pelo uso das vestimentas nas cenas exibidas e pela atuação/participação nas categorias dos bailes. Muitas vezes, os participantes destes eventos confeccionam os próprios trajes para concorrer nas categorias. De acordo com o depoimento de Labeija, muitos deles não têm o que comer, onde dormir e muitas vezes comentem furtos para terem recursos para a confecção das peças.

No contexto dos bailes, as roupas são essenciais para a apresentação nas categorias. Os participantes, ao desfilarem, são performáticos e exibem seus corpos em movimentos que dão vida às temáticas de cada categoria. Pode-se dizer que expressam a "verdadeira" personalidade e, talvez, os verdadeiros desejos e sonhos. Uma das categorias, por exemplo, é a Cena Militar (Military Scene), a qual, pode exprimir o desejo de ser um militar. Na categoria Executivo (Executive Realness), que pode ser visualizada a partir da Imagem 2 - Executivos no Baile, observa-se a necessidade do uso de um traje típico de executivos: o terno completo, gravatas, camisa social, sapato social e a composição final com a pasta de mão: 
Imagem 2 - Executivos no Baile

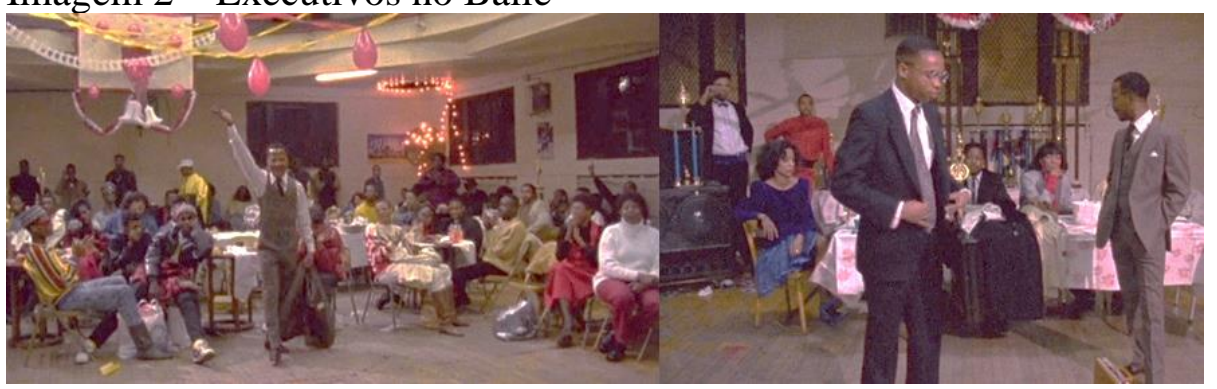

Fonte: imagem extraída do documentário Paris in Burning (1990)

Ao exibir as cenas retratadas pela Imagem 2, Doran Corey, uma das drags entrevistadas, também famosa no ambiente dos bailes, faz a seguinte observação sobre essa categoria, levando em consideração o traje, a realidade social e a sexualidade:

"Na vida real, você só trabalha como executivo se tiver a formação educacional e a oportunidade. Mas você só não é um executivo por causa das imposições sociais. É a mais pura verdade. Não é fácil um negro conseguir algo. E quem consegue costuma ser hétero. Num salão de baile, você pode ser o que bem quiser. Você não é um executivo, mas parece um. Assim você mostra ao mundo hétero que pode ser um executivo. Que se tivesse a chance, poderia ser, pois se parece com um. E isso é uma realização. Seus colegas e amigos dizem: 'Você daria um ótimo executivo"” (PARIS IS BURNING, 1990).

A partir da fala de Doran é possível observar o papel da moda na apresentação das categorias e a possibilidade, através das roupas, de ser aquilo que almeja, o que, no ambiente externo aos bailes, sob um contexto heteronormativo hegemônico, não seria, a princípio, aceitável sem qualquer tipo de preconceito. Nesta realidade, a sexualidade, a identidade de gênero pode impor restrições ao lugar que se deseja ocupar no mercado. Isso ainda pode ser agravado pelo racismo (como denunciado na fala acima), e pela falta de formação adequada e oportunidades que não são dadas aqueles que, no espaço urbano são relegados às periferias, à margem das classes elitizadas. Através desta fala, Doran escancara as desigualdades sociais, bem como as opressões e repressões determinadas pelas relações de poder (de gênero) presentes nos territórios.

Na categoria Alta-costura Parisiense, o próprio nome se refere à moda. A Imagem 3 - Alta-costura Parisiense registra os trajes desfilados no documentário:

Imagem 3 - Alta-costura Parisiense 


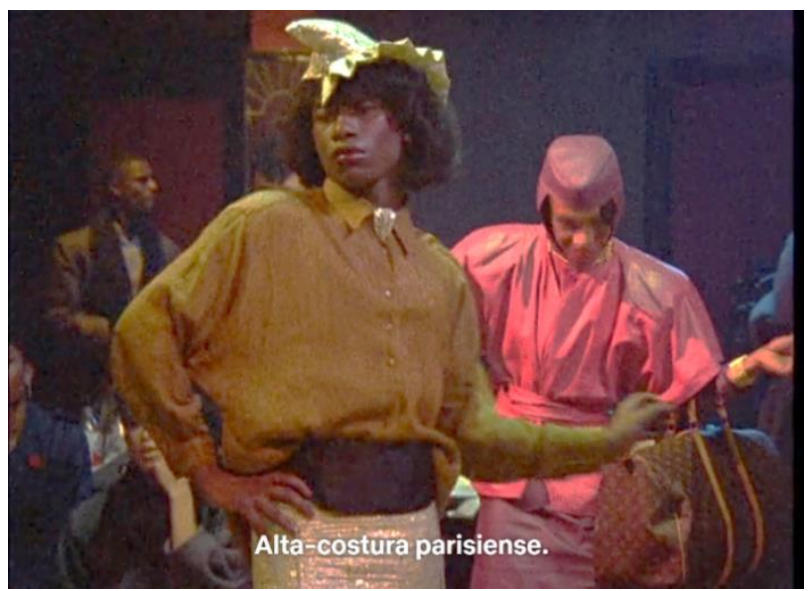

Fonte: imagem extraída do documentário Paris in Burning (1990)

A moda para esta categoria apresenta papel primordial desde o nome até os estilos de roupas que devem ser desfilados. Observa-se que a bolsa que aparece na imagem acima é da marca de luxo Louis Vuitton ${ }^{10}$, mundialmente reconhecida, inclusive, por ter confeccionado malas com a logomarca da casa Vuitton e que são sinônimos de status e poder de compra. Uma autentica mala Vuitton custa em torno de R $\$ 9.000,00^{11}$. Já o conceito de Alta-costura representa, segundo informações do site Fédération de la Haute Couture et de la Mode ${ }^{12}$, uma "exceção francesa" que mistura tradição de excelência e modernidade. As coleções de alta-costura são desfiladas duas vezes ao ano. Somente as empresas, as marcas aprovadas por uma comissão dirigida pela Chambre Syndicale de la Couture, mantida pelo Ministério da Indústria Francês, podem se qualificar como alta-costura. Portanto, é somente na França que é possível encontrar a alta-costura original. Algumas marcas que são membros e desfilam na semana de moda de Alta-costura de Paris: Chanel, Dior ${ }^{13}$, Givenchy ${ }^{14}$, Jean Paul Gaultier ${ }^{15}$, Maison Margiela $^{16}$ e Schiaparelli ${ }^{17}$. Ressalta-se que as coleções de alta-costura são acessíveis somente às classes de alto poder aquisitivo.

Outra categoria similar à anterior é a Alta-costura Noite. Neste momento do documentário há uma polêmica sobre necessidade de se carregar uma bolsa para compor o visual Alta-costura Noite, como pode ser observado na seguinte fala: "A gente vê isso

\footnotetext{
${ }^{10}$ Para maiores informações, consultar site da marca: https://us.louisvuitton.com/eng-us/homepage.

${ }^{11}$ Para maiores informações consultar site da marca: https://br.louisvuitton.com/por-br/produtos/keepall55-bandouliere-monogram-000698.

${ }^{12}$ Fedeation de la Haute Couture et de la Mode. Disponível em: https://fhcm.paris/en/.

${ }^{13}$ Para mais informações, consultar site da marca: https://www.dior.com/pt_br.

${ }^{14}$ Para mais informações, consulta site da marca: https://www.givenchy.com/us/en-US/homepage.

${ }^{15}$ Para mais informações, consultar site da marca: https://www.jeanpaulgaultier.com/pt-br/.

${ }^{16}$ Para mais informações, consultar site da marca: https://www.maisonmargiela.com/us.

${ }^{17}$ Para mais informações, consultar site da marca: https://www.schiaparelli.com/en.
} 
no Canal 7 [...]. A bolsa é obrigatória. É preciso levar alguma coisa para completar uma mulher.” (PARIS IS BURNING, 1990). Nesta fala observa-se a importância do acessório de moda para compor todo o traje que está sendo exibido. Nota-se ainda a fonte de onde tais referências de moda são extraídas: da televisão. Como visto anteriormente, Calanca (2008) cita o papel das atrizes e cantoras como referências de moda e beleza. Pode-se dizer também que a identificação com o gênero feminino na composição do traje depende de um acessório - a bolsa - para que, de fato, possa ser identificado como uma mulher. A partir da Imagem 4 - Alta-costura Noite é possível verificar algumas roupas desfiladas nesta categoria:

\section{Imagem 4 - Alta-costura Noite}

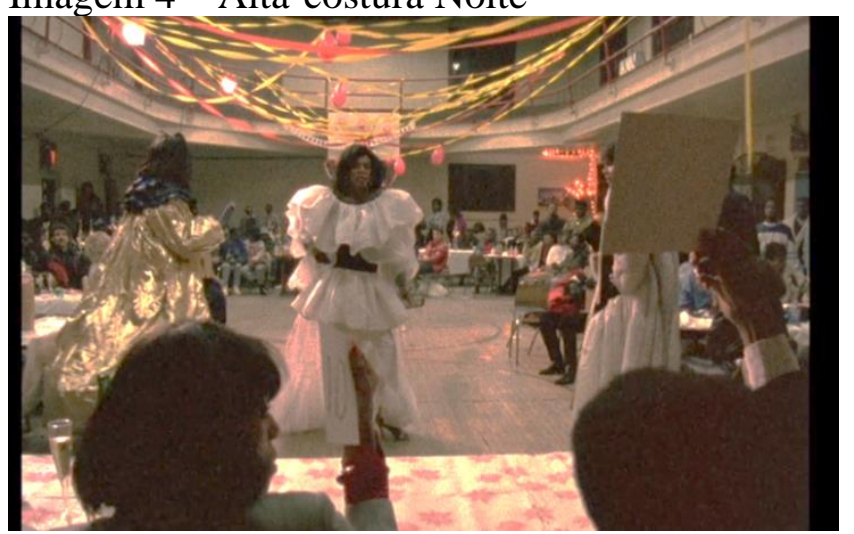

Fonte: imagem extraída do documentário Paris in Burning (1990)

O documentário aborda ainda inúmeras questões, como a prostituição, o abandono da família, e a vida junto às pessoas que estão na mesma condição, que vivem a mesma realidade. A questão da sexualidade, no seio familiar, foi, para alguns dos entrevistados, muito conturbada além da rejeição pelos familiares. Um exemplo, é a seguinte fala de Pepper Labeija:

"Minha mãe sabia dos troféus, mas eu dizia que eram do basquete. Eu ganhei troféus no atletismo. Eu caminhava na Rua 145 com minhas amigas. Vestindo hot pant branca, blusa de chiffon, com rabo de cavalo. Meu pai esperava o sinal abrir e me viu, me reconheceu do carro. Foi para a casa antes de eu chegar e disse à minha mãe: 'Seu filho é uma mulher.' Ela não me pressionou nessa época. Alguns meses depois, ela notou que eu tinha peitos, e começou a juntar os pontinhos. Ela ficou arrasada. 'Como tem peitos maiores que os meus? E unhas compridas. Está virando uma mulher bem diante de mim. Não posso ter cabeça erguida. Tenho vergonha.' Ela ainda me amava, mas e a pentelhação, ai, meu Deus, com as roupas femininas. Se eu escondia roupa de mulher no armário e minha mãe achava, ela destruía. Queimou um casaco de vison. Fiquei arrasada. Reconheceu que o perfume era Jungle Gardenia, que eu gostava. E disse: 'Esse casaco é seu.' Ela desceu, foi aos fundos do prédio e queimou. Eu fiquei chorando que nem neném. Se eu usar 
bigode e tal, tudo bem. Não me quer de roupa de mulher, não aguenta." (PARIS IS BURNING, 1990).

A fala de Pepper retrata a mentalidade do modelo dual de sexualidade heterormativo como informam os autores citados anteriormente. Quem não "encaixa" neste modelo se torna passível de sofrer repressões e preconceitos até mesmo dentro da própria casa. Muitos abandonam as famílias e se instalam em bairros como o Harlem. Juntos, vivem em casas sob a tutela de outras drags mais velhas e com mais experiências nos bailes. Estas são chamadas de "mães", como é o caso de Pepper Labeija, mãe da Casa de Labeija. Membros destas mesmas casas competem nos bailes.

\section{Considerações finais}

Assistir o documentário Paris is Burning é entrar em contato com um universo da realidade, cujos sujeitos não podem expressar sua essência e autenticidade devido aos imperativos de um modelo opressor e que procura banir qualquer forma de expressão alternativa ao modelo dual de sexualidade heterormativo. Tal modelo é vendido através dos inúmeros meios de comunicação e sob diferentes roupagens: estilos de vida, casas, carros, roupas, viagens, os quais são acessíveis, no entanto, a uma pequena parcela da sociedade. Em meio a toda esta oferta, permeiam os padrões heteronormativos. À margem destes, ficam os LGBTQ+ e também os pobres e negros. Excluídos deste "contexto ideal", eles encontram nos bailes o espaço onde seus os corpos podem fluir de forma livre, sem repressões. Constituem nos bailes o seu território.

O corpo como forma de expressão pode ser a materialização dos sonhos e dos desejos, sobretudo, através do papel de representação que a moda pode proporcionar. A partir do conceito de corporeidade, tem-se nos bailes identidades que fluem livremente através de corpos performáticos que desfilam suas roupas de gênero.

Os trajes aparecem como diferencial destes corpos transgressores da heteronormatividade, são formas de expressão desses sujeitos, das suas vontades, da criatividade e formas de ver e viver o mundo. Nos bailes, percebe-se que a roupa possui papel fundamental, principalmente para atender aos critérios de uma determinada categoria de competição.

O racismo, a homofobia e as relações de poder fazem parte de uma teia que exprime as desigualdades que permeiam a vida destas pessoas. São corpos de resistência, de sobrevivência, ainda que nem todos consigam sobreviver à violência de gênero, como 
foi o caso de uma das entrevistadas no longa: Venus Xtravaganza, assassinada em um quarto de hotel.

\section{Referências bibliográficas}

ANDRÉ, Isabel Margarida. O Gênero em Geografia: introdução de um novo tema. Finisterra: Revista Portuguesa de Geografia. vol. 25 n. ${ }^{\circ}$ 50, p. 331 - 348. Lisboa, 1990. BOUCHER, François. História do Vestuário no Ocidente: das origens aos nossos dias. São Paulo: Cosac Neify; tradução de André Telles, 2010.

BRAUDEL, Fernand. Civilização Material, Economia e Capitalismo, Séculos XV - XVIII

- Volume 1: As Estruturas do Cotidiano. Tradução Telma Costa. São Paulo, Martins Fontes, $1^{\text {a }}$ edição brasileira, 1995.

CALANCA, Daniela. História Social da Moda. São Paulo: Editora Senac; tradução de Renato Ambrósio, 2008.

JOHNSTON, Lynda; LONGHURST, Robyn. Space, place and sex: geographies of sexualities. Rowman \& Littlefi eld: Lanham, 2010.

KARSTEN, Lia, MEERTENS, Donny. La geografia del género: sobre visibilidad, identidad y relaciones de poder. Documents d'Anàlisi Geogràfica, [en línea], n. ${ }^{\circ}$ 19-20 (1992), pp. 181-93.

LAN, Diana. Violencia de género, circuitos espaciales y micromachsismos. In: Diálogos ibero-latino-americanos sobre geografias feministas e das sexualidades. Organizado por Joseli Maria Silva, Márcio Jose Ornat e Alides Baptista Chimin Junior. Onta Grossa: Todapalvra, 2017.

SILVA et al. O corpo como elemento das geografias feministas e queer: um desafio para a análise no Brasil. In: Geografias malditas: corpos, sexualidades e espaços. Organizado por Joseli Maria Silva, Márcio Jose Ornat e Alides Baptista Chimin Junior. Onta Grossa: Todapalvra, 2013.

\section{Sites consultados:}

BHAZ. Disponível em: https://bhaz.com.br/2019/09/18/bh-festival-drag-de-rua-degracal. Acesso em: 01/10/2019.

CHANEL. Disponível em: https://www.chanel.com/pt_BR/. Acesso em: 03/12/2019.

FASHION FOWARD - FFW. Disponível https://ffw.uol.com.br/noticias/moda/edicao-historica-do-spfw-traz-irreversivel-quebrade-padroes-dentro-e-fora-das-passarelas/. Acesso em: 01/12/2019. 
FASHION

FOWARD

FFW.

Disponível

em:

https://ffw.uol.com.br/noticias/moda/conheca-sam-porto-o-primeiro-homem-trans-adesfilar-no-spfw/. Acesso em: 01/12/2019.

FEDEATION DE LA HAUTE COUTURE ET DE LA MODE. Disponível em: https://fhcm.paris/en/. Acesso em: 03/12/2019.

JENNIE LIVINGSTON. Disponível em: https://www.jennielivingston.com/about. Acesso em: 02/12/2019.

LOUIS VUITTON. Disponível em: https://us.louisvuitton.com/eng-us/homepage. Acesso em 03/12/2019.

LOUIS VUITTON. Disponível em: https://br.louisvuitton.com/por-br/produtos/keepall55-bandouliere-monogram-000698. Acesso em 06/12/2019.

NETFLIX. Disponível em: https://www.netflix.com/. Acesso em: 01/12/2019.

SUNDANCE INSTITUTE. Disponível em:

https://www.sundance.org/festivals/sundance-film-festival.Acesso em: 02/12/2019. 